WellBeing International

WBI Studies Repository

$12-2008$

\title{
Faecal-Centric Approaches to Wildlife Ecology and Conservation; Methods, Data and Ethics
}

\author{
C. T. Darimont \\ University of Victoria, darimont@uvic.ca \\ T. E. Reimchen \\ University of Victoria \\ H. M. Bryan \\ University of Saskatchewan \\ P. C. Paquet \\ University of Calgary
}

Follow this and additional works at: https://www.wellbeingintlstudiesrepository.org/ethcbio

Part of the Animal Studies Commons, Bioethics and Medical Ethics Commons, and the Other Ecology and Evolutionary Biology Commons

\section{Recommended Citation}

Darimont, C. T., Reimchen, T. E., Bryan, H. M., \& Paquet, P. C. (2008). Faecal-centric approaches to wildlife ecology and conservation; methods, data and ethics. Wildlife Biology in Practice, 4(2), 73-87.

This material is brought to you for free and open access by WellBeing International. It has been accepted for inclusion by an authorized administrator of the WBI Studies Repository. For more information, please contact wbisr-info@wellbeingintl.org.

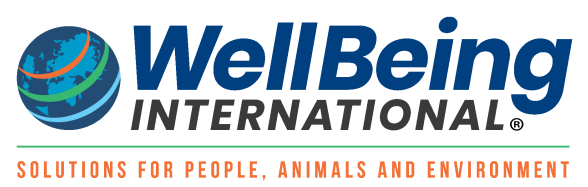




\title{
DISCUSSION FORUM
}

\section{Faecal-Centric Approaches to Wildlife Ecology and Conservation; Methods, Data And Ethics}

\author{
C.T. Darimont ${ }^{1,2, \S}$, T.E. Reimchen ${ }^{1}$, H.M. Bryan ${ }^{2,3}$ \& P.C. Paquet ${ }^{2,4}$
}

' Department of Biology, Box 3020, Stn. CSC. University of Victoria, Victoria, British Columbia, Canada, V8W 3N5

${ }^{2}$ Raincoast Conservation Foundation. Box 76, Denny Island, British Columbia, Canada, V0T 1B0

${ }^{3}$ Department of Veterinary Pathology. 52 Campus Drive. University of Saskatchewan, Saskatoon, Saskatchewan, Canada, S7N 5B4

${ }^{4}$ Faculty of Environmental Design, Professional Faculties Building, Room 2182 University of Calgary, 2500 University Drive NW, Calgary, Alberta, Canada,T2N 1N4

$\S$ Corresponding author. Current address: Department of Environmental Studies, 405 ISB, University of California, 1156 High Street, Santa Cruz, California, USA, 95060

Email addresses: CTD: darimont@ucsc.edu

TER: reimchen@uvic.ca

HMB: heather.bryan@usask.ca

PCP: ppaquet@sasktel.net

\begin{tabular}{ll}
\hline Keywords & Abstract \\
British Columbia, & Abundant and commonly encountered in the field, wildlife faeces have long \\
Conservation, & attracted scientists. Recent advances in molecular techniques, however, \\
Ecology, & especially when coupled with creative study designs, can now yield a \\
Ethics, & great variety of high quality data. Herein, we review the opportunities \\
aalues, & conservation questions using wolves of coastal British Columbia, Canada, \\
Non-invasive, & as a case system. We begin by discussing methodological considerations, \\
Policy, & which should have broad applicability to any wildlife study system. We \\
Scat, & then summarize the extensive and unique variety of data that has emerged \\
Wildlife, & from our 'facts from faeces' approach with wolves, which has ranged from \\
Wolf & descriptive autecology to process-oriented hypothesis-testing to applied \\
& conservation management. We conclude by contrasting this non-invasive \\
approach with radio-collaring in an ethics framework. We contend that \\
when the two methods are equally efficacious in answering required \\
research questions, scatology become the only ethical option, a perspective \\
increasingly codified as policy governing research activities.
\end{tabular}

\section{Introduction}

In no sense peculiar, all animals are united in the imperative to eliminate bodily waste. Far from waste, however, faeces have long attracted naturalists and scientists interested in the information it contains. Early last century, Seton [1] introduced 'scatology' to the mammalogy literature. In subsequent decades, copious data about life history, population trends, and genetic structure have been derived from faeces [reviews in 2,3]. Such 'facts from faeces' are potentially myriad, ranging from detailed foraging information about yesterday's meals to evolutionary information that traces lineages over millennia, extracted from minute quantities of DNA in scats. Currently, data that could not even be envisioned last decade are emerging, following advances in molecular techniques and creative study designs.

In addition to potentially rich data sources, faeces have extra qualities that should attract researchers. First, they are ubiquitous. In many cases, they are the most evident and easily-recognized sign in the field [4]. Also, in contrast to techniques like 
capturing and radio collaring, picking up what animals leave behind has no obvious or direct observer influence on animal behaviour [5]. Such an ethical criterion might be important to many researchers in today's world, as we explain below.

Herein, our central objective is to stimulate discussion among biologists and other wildlife professionals about the practical, scientific and ethical dimensions of wildlife scatology. We do not outline the complete scope of questions that now can be addressed using faeces; we instead direct readers to Kohn and Wayne [3] for the most recent general review. Subsequent reviews that focus on faecal-sourced DNA include methods to: determine presence and distribution of species [6], identify prey in scats [7], genotype and estimate abundance [8,9], and preserve DNA in scat samples [10]. Also, Wasser et al. [11] reviewed hormonal assays from faeces, and Allan and Craig [12] appraised copro-antigen tests to detect infectious organisms. Similarly, our aim is not to review the pros and cons of frequently employed methodological alternatives to scatology, including radio-telemetry, except in the context of contrasting ethical implications of scatology with telemetry. For a thorough review of radio telemetry, we direct readers to recent and comprehensive books [e.g., 13, 14].

Seminal work on wolves by Murie, McTaggart-Cowan, and other pioneering naturalists relied to great extent on patient observation and examination of what is readily observed in wolf country: wolf faeces $[15,16]$. More than a half-century later, we offer our work on wolves (Canis lupus) of coastal British Columbia (BC; Fig. 1 ), which is almost entirely faecal-centric, as a case system to describe the fusion of this long-standing naturalist's technique with contemporary analytical and molecular tools. In our study area, the primary conservation concern for wolves is industrial logging and harvest of marine food resources for wolves like salmon (Oncorhynchus spp.) $[17,18]$. Consequently, these conflicts over resources between humans and wolves provide conservation context to our work and this review.

We begin this integrative essay with methodological and safety considerations of working with faecal material. We follow by outlining the range of information we have gathered from wolf faeces, highlighting the opportunities and challenges that have emerged, paying particular attention to potential sources of bias. We conclude by examining ethical considerations related to scatology and its alternatives, which in part led us to pursue this non-invasive technique.

\section{Methodological considerations}

Several factors conspire to make wolf faeces more available to researchers than would be predicted based on the species' naturally low density and elusive nature. First, as endothermic carnivores with high trophic requirements, wolves consume and excrete a large amount of food resources. In captive feeding experiments, Weaver [19] noted an average of about 4 defecations per day. Second, wolves are highly mobile, and able to distribute their faeces widely throughout the landscape. Data from Poland suggest that, whereas rates of urine marking and ground scratching show large seasonal and spatial variation, deposition rates of scat show little variation over time and space [20]. Third, wolves often deposit faeces in visually conspicuous locations, including trail or corridor intersections where there is presumably more conspecific 'traffic' [21, 22]. For any species, faecal-centric methods differ fundamentally from more orthodox (whole animal-centric; e.g. radio-collaring) approaches in several ways, some of 


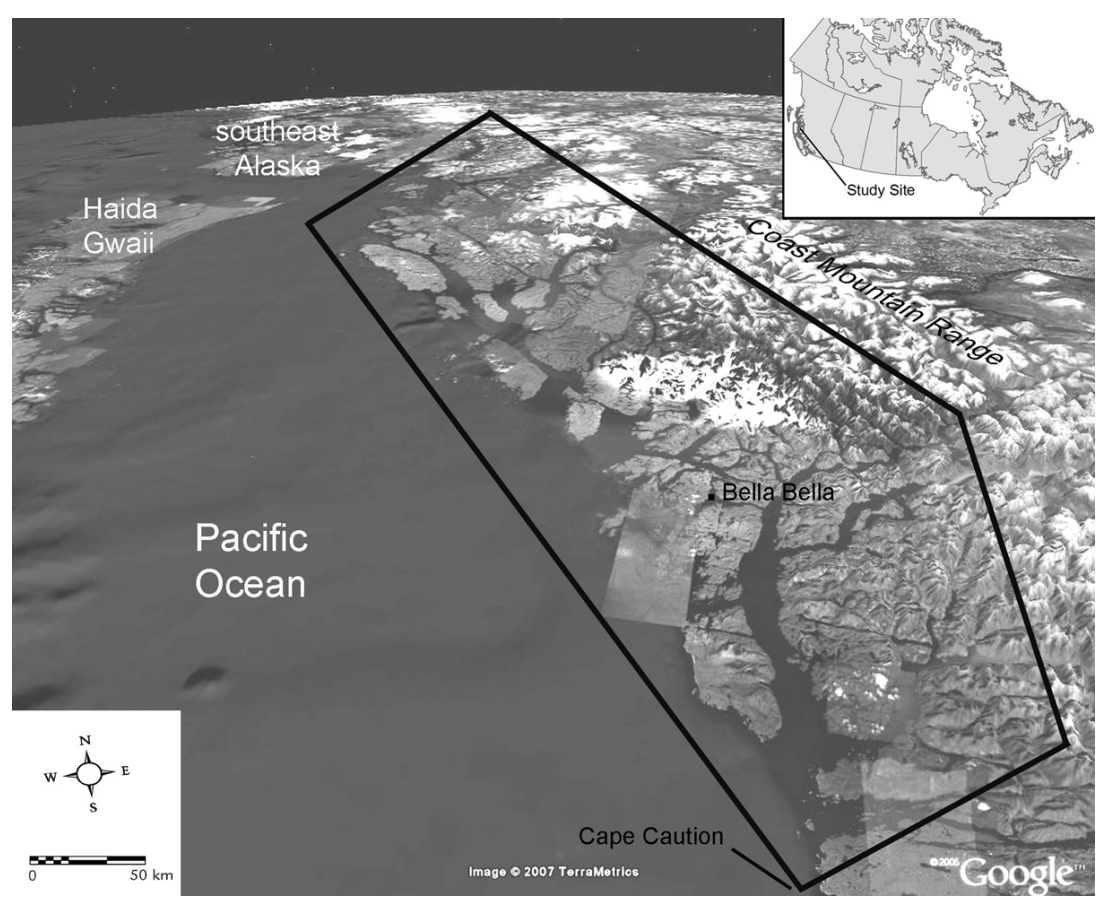

Fig. 1. Study area on British Columbia's central and north coast, Canada $\left(60,000 \mathrm{~km}^{2}\right)$. Basemap from www.earth.google.com.

which require foresight to prevent or minimize potential sources of error and bias. First, because scats are collected in the absence of the depositing individual, the identity of species may not be immediately known. Scats can be distinguished among species based on size and other morphological characteristics [4]. In some cases, however, species-specific genetic markers might be necessary to reliably distinguish among species [23].

Second, unless microsatellite genetic markers are amplified from faeces (or animals are observed while defaecating), a researcher cannot assign scat samples to individuals. Consequently, examining foraging variation among individuals for example - a contemporary topic [review in 24] - is not possible. Fedriani and Kohn [25], however, did extract microsatellite markers from faecal samples to document persistent variation in foraging behaviour among individual coyotes (C. latrans).

Third, a faecal sample identifies the location where an animal was at one time, but not where it has been or where it has since travelled. 'Time stamps' on faecal deposition may be estimated, however, with repeated sampling of established transects. We have used seasonal timestamps by repeatedly sampling transects at the end of spring, summer, and fall seasons. Although conditions will vary in other areas, faeces decompose rapidly in coastal rainforests [26]. Thus, we considered each collection representative of the season in which it was collected. Timescales could potentially be finer. Although not well described, estimates of typical 'gastric emptying times' for wolves are rapid, ranging from 8 to 56 hours [19, 27-29]. Time stamps may be particularly precise in areas of constantly accumulating snow. These conditions, combined with (time-sensitive) hormonal information within faeces, could evaluate 
fine-scale aspects of ecology and behaviour. For example, investigations into stress hormones in wolf scats have shown relationships with anthropogenic stressors [30] and intra-specific social interactions [31].

Fourth, owing to logistical and resource constraints, researchers typically must subsample large landscapes for wolves and other wildlife. As a result and unless transects are strictly random, researchers must assess the relevance or severity of potential spatial biases. For example, in our largely road-less study area our surveys are biased to areas closer to the shoreline, where boats provide the only access. Consequently, and depending on landmass configuration, we had originally predicted that prey items recovered from faeces might be biased towards marine items [32, but see below]. Also, in wolves and other social carnivores, different individuals (i.e., territorial vs. non-territorial) might conceal scats [33] or make them conspicuous [21, 22].

These potential biases need to be evaluated in the context of proposed research programmes. We had the opportunity to assess how sampling might have proceeded if applied randomly across the study area. In two seasons of random transects on which we enumerated deer pellets $[34,35]$, we also noted the presence of wolf faeces on or within visual range of our 1-m wide transects. After $110 \mathrm{~km}$ of transects, we observed only six wolf faeces. In the questions we have posed, we find the trade-offs acceptable (especially given that we employ an independent isotopic data set; see below).

Collection of wildlife faeces is straightforward but requires some foresight to maximize sample size and information available within samples. Clearly, sampling known travel routes will maximize samples but additional considerations are important. Field technicians travelling slowly by foot or ski would likely detect more than those using trucks, bicycles, or other relatively fast vehicles. Also, if only one sampling episode is required, spring or winter may be preferable in areas where abundant vegetation in summer may conceal faeces. Moreover, months with colder temperatures, which slows DNA degradation, would be most valuable if genetic material from faeces is sought. The use of 'scat-sniffing' dogs (Canis lupus familiaris) can also be useful [36].

\section{Safeguards against faecal pathogens}

Humans and wildlife can host some of the same species of parasites, placing researchers at risk of contracting diseases from faecal samples. A diverse suite of parasites release propagules in the form of eggs, larvae, and oocysts in scats. If inadvertently ingested by humans, some propagules might develop partially or fully, resulting in diseases with mild to severe symptoms.

In wolves, among the most serious concerns are Echinococcus granulosus and E. multilocularis, tapeworms that can invade internal organs and cause severe to lethal damage [review in 37]. The nematode Toxocara is also an important concern for human health, as larvae can migrate anywhere in the body, potentially causing permanent damage to eyes, brain, liver, and lungs as well as other tissues [38]. Other genera that may infect humans include the hookworms Ancylostoma [39] and Uncinaria [40], the whipworm Trichuris [41], and the protozoans Giardia [42] and Cryptosporidium [43]. Faecal bacteria such as Escherichia coli also pose health risks to faecal-centric workers [44].

Because of potentially severe consequences of infection, those who work with wolf and other wildlife faeces should take appropriate cautionary measures to prevent 
ingestion of parasite propagules from faeces. Propagules can be ingested accidentally via contaminated clothing, equipment, food, or drink or by inhalation of faecal dust particles containing propagules. Therefore, researchers should consider wearing protective clothing and using biosafety cabinets in laboratories. Risks can be further reduced by freezing samples for 72 hours at $-80^{\circ} \mathrm{C}$, which is thought to kill most parasite stages, including Echinococcus eggs [45]. Autoclaving faeces is another way to kill parasite propagules, but high temperatures might compromise sample quality for intended analyses.

\section{Results from faecal-centric research on wolves of coastal British Columbia}

Over seven years, we have conducted four field seasons ( April to October) plus additional episodic sampling in other years. To address a number of questions, we sampled on two spatial scales: a $3,000 \mathrm{~km}^{2}$ area comprising eight social groups (i.e. packs) we sampled intensively, and the entire central and north coast of $\mathrm{BC}$ (roughly $60,000 \mathrm{~km}^{2}$ ) we sampled occasionally (Fig. 1). Below we summarize results from our studies, showing how a range of ecological, evolutionary and conservation questions could be addressed in any system using a fecal-centric approach.

\section{Distributional Data}

Assessing distribution is a critical first step in the conservation of flora and fauna. Given the vulnerability of isolated populations, such an approach is especially valuable in archipelagos or populations thought to exist in remnant islands of habitat in humanaltered landscapes [46]. Likewise, such data can be compared to predictive models of wildlife presence [47], or to survey for their presence in previously unstudied areas. We used this method for the latter in coastal BC.

In 2000 and 2001, we surveyed the entire central and north coastal BC. We documented wolf presence primarily from observation of scat. During these initial surveys, we observed wolf faeces in all mainland watersheds $(n=42)$ and 34 of 36 sampled islands. Notably, the most isolated islands on which we noted wolves were $5-\mathrm{km}$, 7-km, and 13-km from other large landmasses [48].

This preliminary descriptive work filled a fundamental gap in our ecological knowledge and informed our developing research programme. At that stage, we were not able to determine if wolf faeces observed on islands came from multiple or solitary animals, or if wolves were resident or transient. Therefore, this snap-shot sampling yielded information about what islands wolves could reach but not how wolves might use these natural fragments over time. We proposed that many of the sampled islands were not large enough to continuously support wolves. By continuing our surveys and documenting the presence of fresh faeces, we assessed which island features best predicted wolf presence over time (immediately below).

\section{Dynamic island occupancy by wolves}

During the subsequent five years, repeated sampling ( $\mathrm{n}=50$ islands) for wolf faeces provided insights into dynamic distributional patterns on islands. Given their ability to colonize islands, we postulated that coastal wolves could form packs whose 
territories can include groups of islands. Our overarching research hypothesis was that distances among islands, their juxtaposition and geometry, and prey availability influenced wolf presence on islands.

Controlling for survey effort (i.e. number of sampling episodes), several parameters contributed to predictive models to explain the presence of wolves on islands over time. Among landscape features, island area was most important, whereas island isolation was much less important. We believe island size influences the quantity and quality of resources available to wolves. For example, larger islands likely have greater food resources overall and those prey populations are probably more stable [48]. Thus, wolves can maintain longer residency times on these islands, which would increase the probability of their detection during our surveys. Isolation was not important, likely because of the swimming proficiency of wolves [34, 48].

\section{Distribution of wolf prey}

Given the broad dietary niche of wolves, prey remains in their faeces can also inform researchers about other species in remote and poorly studied areas. In our area for example, accounts of mammal occurrence on islands were largely unknown. Although earlier distribution reports using more traditional survey techniques (i.e. observations, trapping) have been valuable [49], there were no complete records. We contributed data by benefiting from wolves that 'sampled' the mammalian community and presented the remains of these prey in their faeces.

Using prey identification techniques [50], we contributed several new records for mammals on BC's coastal islands. Among these, we detected marten (Martes americanus), black-tailed deer (Odocoileus hemionus), and ermine, (Mustela erminea) in wolf faeces on islands where they had not been previously documented [51]. Similarly, this approach led to the detection of moose emigration to coastal $\mathrm{BC}$, a recent and previously undocumented phenomenon regarding this elusive but potentially important prey item and vector of disease [52]. Finally, hair from prey we extracted from wolf faeces provided distributional and isotopic data for an examination of carcass use by scavenging beetles [53].

\section{Foraging information}

After learning where wolves and their potential prey reside in the archipelago, faecal remains also allowed us to investigate what food resources might be important to wolves and how this might vary among areas. Across their Holarctic range, wolves have close ecological and evolutionary associations with ungulates [54, 29]. Consequently, we expected little departure from a diet dominated by black-tailed deer, the region's only well-distributed ungulate. After examining prey remains in more than 3000 samples collected throughout the varied landscape and over several years as well as drawing on an independent isotopic dataset, we outline results below that are contrary to these expectations.

At the interface of land and sea, wolves showed a tremendously broad dietary niche. We have detected a minimum of 14 terrestrial and marine mammals, and several species of the following: salmon (Oncorhynchus spp.), intertidal invertebrates, birds, and vegetation. Of all these items, however, only a few - represented by both 
terrestrial and marine species - dominated diet [32,35,55].

Departures from an ungulate diet related to landscape variation. In our earliest dataset ( $n=595$ faeces) collected across the entire study area, major biogeographic patterns emerged. For example, whereas mainland wolves consumed mostly ungulates (during spring and summer), the probability of detecting deer in wolf faeces collected on islands varied with isolation. Specifically, this probability was influenced primarily by island distance to mainland (not by area or inter-landmass distance). Though deer are present there, the probability they were consumed by wolves declined to near zero on the outer-most archipelago, $13 \mathrm{~km}$ from the mainland (Fig. 2). Wolves replaced deer with smaller and mostly marine mammals as well as salmon, when seasonally available. We postulated that population dynamics of deer (and likely wolves) in isolated fragments are less stable and can result in predator-prey disequilibria [32].

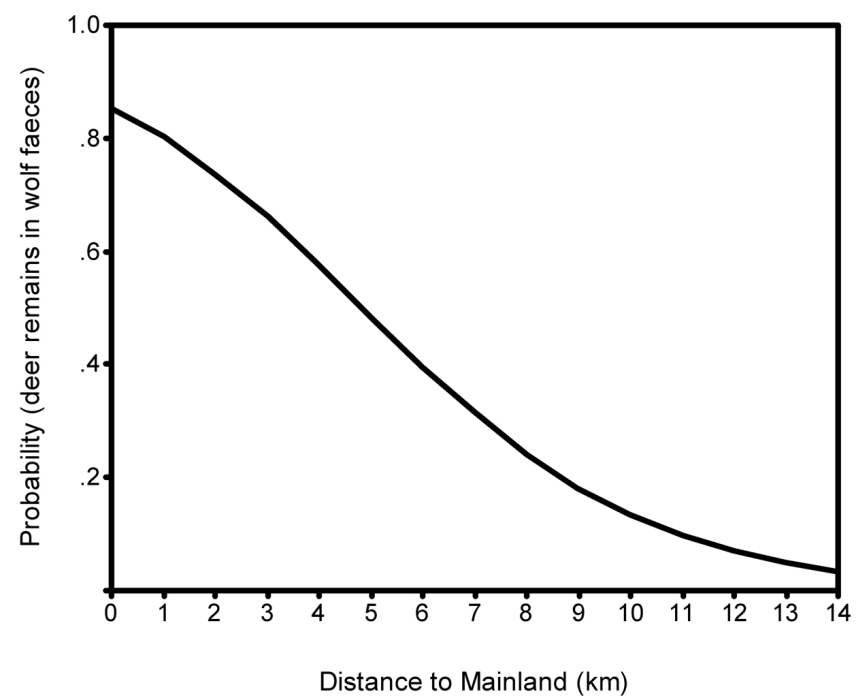

Fig. 2. Probability of deer remains occurring in wolf faeces on islands $(n=30)$ as a function of their distance to the mainland. Samples collected in coastal British Columbia, summers 2000 and 2001. From [32].

Our larger, multi-year and -season data set $(n=2205$ faeces) allowed us to document seasonal dietary changes in a mainland and inner island area of $3000 \mathrm{~km}^{2}$, where eight packs resided. During spring and summer, deer remains occurred in roughly 90 and $95 \%$ of faeces. When salmon become available in autumn, however, the population showed a pronounced dietary shift in which deer consumption among groups was negatively correlated with consumption of salmon, which occurred in $40 \%$ of all faeces and up to $70 \%$ of faeces for some groups. Notably, the magnitude of this seasonal dietary shift was related primarily to estimates of salmon availability, not deer availability, in each home range and year, suggesting wolves forwent deer to target salmon [56]. Although this wolf-prey association during fall departs from a 'wolf-ungulate' model, it is consistent with adaptive explanations based on safety, nutrition, and energetics [57, 58].

During this study, we also had the opportunity to examine how consistent our faecal data were to independent isotopic data [review in 59], derived from shed hair from the same wolves sampled during the same periods. We found that the seasonal dietary 
shift to salmon as detected by faecal analysis was strongly correlated with intra-hair (i.e. inter-seasonal) shifts in $\delta^{13} \mathrm{C}$ isotopic signatures, which indicated a switch to increased use of marine resources. When more salmon occurred in pack faeces during fall, the pack also showed greater 'seasonal isotopic shifts' to more marine-derived isotopes in their hair during fall (Fig. 3). Concordance of these data sets suggest both methods provide accurate estimates of resource use, and could reliably track seasonal dietary shifts in any consumer-resource system

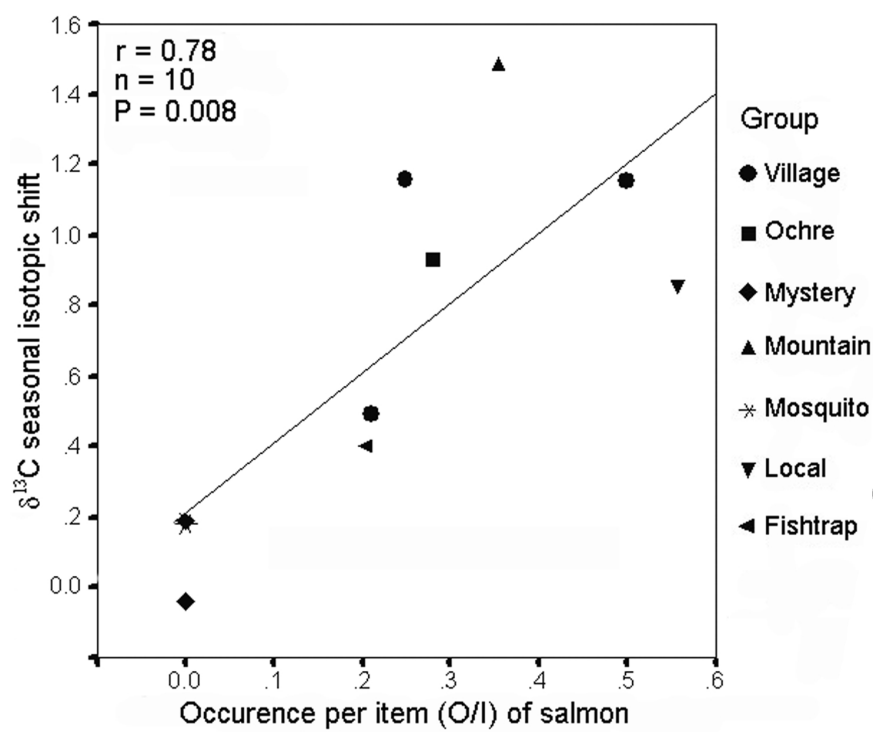

Fig. 3. Salmon (Oncorhynchus spp.) remains in wolf(Canis lupus) faeces expressed as occurrence per item in each group during fall and the mean seasonal isotopic shift, which is the fall minus summer $\delta^{13} \mathrm{C}$ values in wolf hair, averaged among individuals of the same groups grown during the same year. Higher values imply greater marine resource use during fall, when salmon are available. Samples collected in coastal British Columbia, 2001 to 2004. From [56].

In addition to environmental features influencing diet, faecal data have allowed us to detect differences among age groups. Although wolf diet has been extensively studied, little was known about the diet of pups [54]. Dietary differences between or among age classes can increase population niche width and decrease intraspecific competition [60]. Provisioning of young by adults, as do wolves, is one mechanism whereby differences in diet between young and adults may occur [61]. At two homesites (reproductive areas) over two years, we exploited the size differences between adult and pup scats to examine if adult diet differs from pups during summer. We found that pups were provisioned disproportionately more fawn (juvenile deer) than the adults consumed. Among several hypotheses to explain this pattern, we suggested that this provisioning behaviour may be an adaptation to limit parasite transfer to developing pups [55].

\section{Wolves as agents of evolution}

Although to our knowledge not previously exploited, evolutionary information about predator-prey dynamics is also available in carnivore faeces. Specifically, scats 
contain not solely 'prey remains' but also individuals that were selected against by an agent of selection (i.e. predator). This provides the opportunity to compare the traits and ecology of these 'non-survivors' with a random sub-sample of survivors, if such samples can also be acquired. These comparisons of non-survivors to survivors can provide direct evidence of natural selection and its targets [62].

As predators, wolves can be agents of evolutionary selection, removing individuals from a prey population that may differ in ecology, age, nutritional condition, or phenotypic characters from other individuals in the population. Using stable isotopic analysis on the hair of deer 'survivors' (deer hair collected in deer day beds along random transects) and 'non-survivors' (deer hair extracted from wolf faeces), we documented fitness (i.e. survival) differences associated with resource use. Independent of age or body condition effects (which isotopic data did not track), our results suggested that non-surviving deer foraged in forest stands that offered more protein-rich vegetation compared with survivors. This implied an evolutionary tradeoff for deer between nutritional benefits and risk of predation [63].

\section{Fecal-based DNA questions}

We have also successfully extracted DNA from wolf faeces to examine phylogenetic questions. Accurate taxonomy is crucial to conservation because it can identify unique taxa and provide a basis for their protection. Modern designations of subspecies and management units now require molecular data [64]. Accordingly, we have amplified mitochondrial DNA (mtDNA) control region sequences in coastal wolves to compare with those known previously and in samples we acquired from interior regions of BC. Notably, we combined genetic analyses with ecological data (summarized above), arguing that wolves of coastal $\mathrm{BC}$ form a genetically and ecologically divergent group [65].

\section{Faecal monitoring of wildlife parasites}

The current stage of our faecal-centric research programme focuses on parasites, which have effects on individuals, populations, and ecosystems [66]. In coastal B.C., rapid habitat change combined with extreme natural isolation and the presence of parapatric dogs (C. lupus familiarus) might make coastal wolves and other wildlife vulnerable to changes in existing parasite-host dynamics. Gastrointestinal parasites have been studied in wolf populations worldwide [review in 67] but not in our study area.

Our study of parasites is starting with a survey of helminths and protozoans that exploit the canine gastrointestinal tract and release propagules via faeces that can be isolated, identified, and counted. Based on morphology alone, however, we can rarely differentiate parasite propagules in faeces below family or genus level. Therefore, we are combining traditional coprological techniques with molecular techniques such as polymerase chain reaction (PCR) that will allow us to obtain genetic information to identify parasite species and potentially also examine finer-scale ecological questions.

Our initial investigations using faecal assays have revealed at least 16 parasite genera in wolves and 7 in dogs, including several with zoonotic potential, such as tapeworms 
of the family Taeniidae, nematodes Toxocara and Trichuris, and protozoans Giardia and Cryptosporidium. Other parasites found, such as Diphyllobothrium, are likely representative of coastal wolves' fish-eating habits [68].

\section{Ethical Considerations}

We conclude with a discussion of research ethics, not as an aside, but as an important criterion to consider given emerging sensitivities of researchers, funding agencies, and governments. We can endorse scatology (and do here), but decisions ultimately depend on research questions, people involved, and philosophical frameworks. We argue, however, that when a choice of equally efficacious methodologies exists, noninvasive techniques become the only ethical option for researchers.

The first question one might pose is, 'do potential benefits (i.e. information about a population) rendered from traditional invasive studies outweigh potential costs to the individual animals involved?' We believe in some circumstances the answer might be yes [e.g. wolf-human conflict in Yellowstone Park and area (USA); 69]. It is generally the implicit responsibility of individual biologists, however, to decide when disturbance due to field practices is justifiable [70]. If acknowledged at all, most workers claim little to no effect of invasive procedures such as telemetry on their subjects; their claims, however, are not always valid [71].

Our philosophical framework during initiation of our study was informed by data and our own observations that relate to suffering that radio-collared animals can endure. Capturing study animals can result in mortality through stress-induced capture myopathy and complications related to anaesthesia [review in 72]. Moreover, recent work has shown long-term and serious effects of capture on daily movements and body condition following handling [73]. Finally, in our own experiences, even in the absence of obvious complications, we feel profound empathy for individuals restrained and burdened with telemetry transmitters against their will. Although resulting data may aid a population, we nonetheless value each individual beyond their contribution to a population [see also 74]. Many others, including biologists, however, disagree with this contention [75]. We argue, however, that being concerned about an individual animal's suffering is not a trivial concern but should be a central tenet of conservation biology. As wildlife scientists we should be well equipped to recognize animal sentience. Combined, these sentiments motivated us to pursue noninvasive methods.

Others share these perspectives and they are collectively codified as policy in contexts where governing bodies oversee research programs. For example, an expert panel convened by Isle Royale National Park in Michigan (USA) to advise on research methods in wilderness parks challenged wolf researchers and the National Park Service to alter existing handling of wolves and pursue non-invasive methods [76]. For similar reasons, invasive techniques may not be approved by aboriginal groups that claim ownership to territories and their wildlife [e.g. 77]. Since the outset of our work, we have respected the desires of the Heiltsuk First Nation in whose territory we work, who voiced concern over the possibility of wolves with radio-telemetry collars and strongly favoured a non-invasive approach.

Another philosophical consideration we valued was the nature of our relationship with the study animal and its landscape. We believe it is valuable that researchers develop 
an intimate association with, and knowledge of, the landscape. It no longer satisfies us to capturing animals once, affix a radio collar, and then primarily monitor them from a distance. In contrast, walking in the footsteps of wild wolves places us squarely in the 'ecological theatre'. Additionally, we feel that intense and intimate experience in the field confers more value than solely aesthetic. Resulting observations often lead to additional insights and ideas that may not have emerged otherwise.

\section{Conclusions}

Faecal-centric research methods have supported a diversity of examinations in our work and, increasingly, other projects. We have addressed fundamental autecological (e.g. distribution, diet) questions regarding not only wolves but also their prey. Additionally, we have gained insight into several higher-order ecological and evolutionary processes including the influence of biogeography on predator-prey dynamics, ecological linkages between terrestrial and marine environments, and predators serving as evolutionary agents of natural selection.

A similarly faecal-centric approach could have broad utility in other studies on wolves and other wildlife. We have outlined potential opportunities and possible pitfalls, especially sources of biases. How perceived pros and cons compare to the suite of other research methods, and particularly radio telemetry, will vary among projects and investigators, informed by ecological, conservation, socio-political and administrative dimensions. We predict, however, that such non-invasive faecal-centric applications will continue to grow, supported by technical and ethical advances in conservation science and management [78].

\section{Acknowledgements}

We thank the Raincoast Conservation Foundation for funding and supporting the Rainforest Wolf Project since its inception. We also thank the National Geographic Society, Patagonia, WWF Canada, and the following Foundations for funding: Bullitt, McCaw, Summerlee, Vancouver, and Wilburforce. CTD was supported by NSERC Graduate and Postdoctoral Fellowships, HMB by an NSERC Graduate Fellowship, and TER by NSERC operating grant A2354.

\section{References}

1. Seton, E.T. 1925. On the study of scatology. J. Mammal. 6: 47-49. DOI: $10.2307 / 1373469$

2. Putman, R.J. 1984. Facts from faeces. Mammal Rev. 14: 79-97. DOI: 10.1111/j.1365-2907.1984.tb00341.x

3. Kohn, M.H. \& Wayne, R.K. 1997. Facts from faeces revisited. Trends Ecol. Evol. 6: 223-227. DOI: 10.1016/S0169-5347(97)01050-1

4. Rezendes, P. 1999. Tracking and the art of seeing: how to read animal tracks and sign. Second edition. HarperCollins, New York.

5. Wemmer, C., Kunz, T.H., Lundie-Jenkins, G. \& McShea, W. 1996. Mammalian sign. In: Wilson, D.E., Cole, F.R., Nichols, J.D., Rudran, R. \& Foster, M.S. (eds). Measuring and monitoring biological diversity. Standard methods for mammals. Smithsonian Institution Press, Washington, pp 157-176. 
6. Palomares, F., Godoy, J.A., Piriz, A., O`Brien, S.J., \& Johnson, W.E. 2002. Faecal genetic analysis to determine the presence and distribution of elusive carnivores: design and feasibility for the Iberian lynx. Mol. Ecol. 11: 2171-2182.

DOI: 10.1046/j.1365-294X.2002.01608.x

7. Symondson, W.O.C. 2002. Molecular identification of prey in predator diets. Mol. Ecol. 11: 627-641. DOI: 10.1046/j.1365-294X.2002.01471.x

8. Fernando, P., Vidya, T.N.C., Rajapakse, C., Dangolla, A. \& Melnick, D.J. 2003. Reliable noninvasive genotyping: fantasy or reality? J. Hered. 94: 115-123.

DOI: $10.1093 /$ jhered/esg022

9. Lukacs, P.M., Eggert, L.S. \& Burnham, K.P. 2007. Estimating population size from dung-based DNA capture-recapture data. Wildl. Biol. Pract. 3: 83-92.

DOI: $10.2461 /$ wbp.2007.3.10

10. Frantzen, M.A.J., Silk, J.B., Ferguson, J.W.H., Wayne, R.K. \& Kohn, M.H. 1998. Empirical evaluation of preservation methods for faecal DNA. Mol. Ecol. 7: 1423-1428.

DOI: $10.1046 /$ j.1365-294x.1998.00449.x

11. Wasser, S.K., Hunt, K.E. \& Clarke, C.M. 2002. Assessing stress and population genetics through non-invasive means. In: Aguire, A.A., Ostfeld, R.S., Taber, G.M., House, C. \& Pearl, M.C. (eds). Conservation medicine: ecological health in practice. Oxford University Press, Oxford, pp. 130-144.

12. Allan, J.C. \& Craig, P.S. 2005. Coproantigens in taeniasis and echinococcosis. Parasitol. Int. 55: S75-S80. DOI: $10.1016 /$ j.parint.2005.11.010

13. Millspaugh, J.J. \& Marzluff, J.M. 2001. Radio Tracking and Animal Populations. Academic Press, London.

14. Kenward, R.E. 2001. A Manual of Radio Tracking. Academic Press, London.

15. Murie, A. 1944. The wolves of Mount McKinley. U.S. National Park Service Fauna Series Number 5, Washington.

16. Cowan, I.M. 1947. The timber wolf in the Rocky Mountain national parks of Canada. Can. J. Res. 25: 139-174.

17. Schoonmaker, P.K., von Hagen, B., \& Wolf, E.C. 1997. The Rainforests of Home: profile of a North American bioregion. Island Press, Washington.

18. National Resources Council. 1996. Upstream: salmon and society in the Pacific Northwest. National Academy Press, Washington.

19. Weaver, J.L. 1993. Refining the equation for interpreting prey occurrence in gray wolf scats. J. Wildl. Manage. 57: 534-538.

DOI: $10.2307 / 3809278$

20. Zub, K., Theuerkauf, J., Jędrzejewski, W., Jędrzejewski, B., Schmidt, K. \& Kowalczyk, R. 2003. Wolf pack territory marking in the Białowieża primeval forest (Poland). Behaviour 140: 635-648. DOI: $10.1163 / 156853903322149478$

21. Vilà, C., Urios, V. \& Castroviejo, J. 1994. Use of faeces for scent marking in Iberian wolves (Canis lupus). Can. J. Zool. 72: 373-377.

22. Barja, I., de Miguel, F.J. \& Bárcena, F. 2004. The importance of crossroads in faecal marking behaviour of wolves (Canis lupus). Naturwissenschaften 91: 489-492.

DOI: 10.1007/s00114-004-0557-1

23. Farrell, L.E., Roman, J. \& Sunquist, M.E. 2000. Dietary separation of sympatric carnivores identified by molecular analysis of scats. Mol. Ecol. 9: 1583-1590.

DOI: 10.1046/j.1365-294x.2000.01037.x

24. Bolnick, D.I., Svanbäck, R., Fordyce, J.A., Yang, L.H., Davis, J.M., Hulsey, C.D. \& Forister, M.L. 2003. The ecology of individuals: incidence and implications of individual specialization. Am. Nat. 161: 1-28. DOI: $10.1086 / 343878$ 
25. Fedriani, J.M. \& Kohn, M.H. 2001. Genotyping faeces links individuals to their diet. Ecol. Lett. 4: 477-483. DOI: $10.1046 /$ j.1461-0248.2001.00250.x

26. Wallmo, O.C., Jackson, A.W., Hailey, T.L. \& Carlisle, R.W. 1962. Influence of rain on the count of deer pellet groups. J. Wildl. Manage. 26: 50-55.

DOI: $10.2307 / 3798167$

27. Floyd, T.J., Mech, L.D. \& Jordan, P.A. 1978. Relating wolf scat content to prey consumed. J. Wildl. Manage. 42: 528-532.

DOI: $10.2307 / 3800814$

28. Kreeger, T. 2003. The internal wolf: physiology, pathology, and pharmacology. In: Mech, L.D. \&. Boitani, L. (eds). Wolves: behaviour, ecology and conservation. University of Chicago Press, Chicago, pp 192-217.

29. Peterson, R. \& Ciucci, P. 2003. The wolf as a carnivore. In: Mech, L.D. \& Boitani, L. (eds.). Wolves: behavior, ecology, and conservation. University of Chicago Press, Chicago, pp 104-130.

30. Creel, S.M., Fox, J.E., Hardy, A., Sands, J., Garrott, B. \& Peterson, R.O. 2002. Snowmobile activity and glucocorticoid stress responses in wild wolves and elk. Conserv. Biol. 16: 809-814. DOI: $10.1046 / \mathrm{j} .1523-1739.2002 .00554 . x$

31. Sands J.L. \& S.M. Creel. 2004. Social dominance, aggression and fecal glucocorticoid levels in a wild population of wolves, Canis lupus. Anim. Behav. 67: 387-396.

DOI: 10.1016/j.anbehav.2003.03.019

32. Darimont, C.T., Price, M.H.H., Winchester, N.N., Gordon-Walker, J. \& Paquet, P.C. 2004. Predators in natural fragments: foraging ecology of wolves in British Columbia's central and north coast archipelago. J. Biogeogr. 31: 1867-1877. DOI: 10.1111/j.1365-2699.2004.01141.x

33. Rothman, R.J. \& Mech, L.D. 1979. Scent-marking in lone wolves and newly formed pairs. Anim. Behav. 27: 750-760.

DOI: 10.1016/0003-3472(79)90010-1

34. Paquet, P.C., Alexander, S.M., Swan, P.L. \& Darimont, C.T. 2006. The influence of natural landscape fragmentation and resource availability on connectivity and distribution of marine gray wolf populations on the Central Coast, British Columbia, Canada. In: Crooks, K. \& Sanjayan, M.A. (eds.) Connectivity Conservation. Cambridge University Press. Cambridge, UK.

35. Darimont, C.T., Paquet, P.C. \& T.E. Reimchen. In press. Landscape heterogeneity and marine subsidy generate extensive niche variation in a terrestrial carnivore. Journal of Animal Ecology.

36. Smith, D.A., Ralls, K., Davenport, B., Adams, B. \& Maldonado, J.E. 2001. Canine assistants for conservationists. Science 291: 435.

DOI: $10.1126 /$ science.291.5503.435B

37. Eckert, J. \& Deplazes, P. 2004. Biological, epidemiological, and clinical aspects of echinococcosis, a zoonosis of increasing concern. Clin. Microbiol. Rev. 17: 107-135.

DOI: 10.1128/CMR.17.1.107-135.2004

38. Guillot, J. \& Bouree, P. 2007. Zoonotic worms from carnivorous pets: risk assessment and prevention. B Acad Nat Med Paris 191: 67-81.

39. Robertson, I.D., Irwin, P.J., Lymbery, A.J. \& Thompson, R.C.A. 2000. The role of companion animals in the emergence of parasitic zoonoses. Int. J. Parasitol. 30: 1369-1377.

DOI: 10.1016/S0020-7519(00)00134-X

40. Ghadirian, E. 2007. Human infection with uncinaria in north of Iran. Iran J Parasitol 2: 38-41.

41. Dunn, J.J., Columbus, S.T., Aldeen, W.E., Davis, M. \& Carroll, K.C. 2002. Trichuris vulpis recovered from a patient with chronic diarrhea and five dogs. J. Clin. Microbiol. 40: 2703-2704.

DOI: $10.1128 / \mathrm{JCM}$.40.7.2703-2704.2002 
42. Thompson, R.C.A. 2004. The zoonotic significance and molecular epidemiology of Giardia and giardiasis. Vet. Parasitol. 126: 15-35.

DOI: 10.1016/j.vetpar.2004.09.008

43. Fayer, R., Morgan, U. \& Upton, S.J. 2000. Epidemiology of Cryptosporidium: transmission, detection and identification. Int. J. Parasitol. 30: 1305-1322.

DOI: 10.1016/S0020-7519(00)00135-1

44. Edberg, S.C., Rice, E.W., Karlin, R.J. \& Allen, M.J. 2000. Escherichia coli: the best biological drinking water indicator for public health protection. Symp. Ser. Soc. Appl. Microbiol. 29: 106S-116S.

45. Veit, P., Bilger, B., Schad, V., Schäfer, J., Frank, W. \& Lucius, R. 1995. Influence of environmental factors on the infectivity of Echinococcus multilocularis eggs. Parasitology 110: 79-86.

46. MacDonald, S.O. \& Cook, J.A. 1996. The land mammal fauna of Southeast Alaska. Can. Field Nat. 110: 571-598.

47. Mladenoff, D.J., Sickley, T.A., Haight, G.G. \& Wydeven, A.P. 1995. A regional landscape analysis and prediction of favorable gray wolf habitat in the northern Great Lakes region. Conserv. Biol. 9: 279-294. DOI: 10.1046/j.1523-1739.1995.9020279.x

48. Darimont, C.T. \& Paquet, P.C. 2002. The gray wolves, Canis lupus, of British Columbia's central and north coast: distribution and conservation assessment. Can. Field Nat. 116: 416-422.

49. Nagorsen, D.W. 1990. The mammals of British Columbia: a taxonomic catalogue. Memoir Number 4. Royal British Columbia Museum. Victoria.

50. Cuicci, P., Boitani, L. \& Lovaas, A.L. 1996. A comparison of scat-analysis methods to assess the diet of the wolf (Canis lupus). Wildl. Biol. 2: 37-48.

51. Price, M.H.H., Darimont, C.T., Winchester, N.N. \& Paquet, P.C. 2005. Facts from faeces: Prey remains in wolf faeces revise occurrence records for mammals of British Columbia's coastal archipelago. Can. Field Nat. 119: 192-196.

52. Darimont, C.T., Paquet, P.C., Reimchen, T.E. \& Crichton, V. 2005. Range expansion by moose into coastal temperate rainforests of British Columbia, Canada. Divers. Distrib. 11: 235-239. DOI: 10.1111/j.1366-9516.2005.00135.x

53. Hocking, M.D., Darimont, C.T., Christie, K.S. \& Reimchen, T.E. 2007. Niche variation in burying beetles (Nicrophorus spp.) associated with Pacific salmon carcasses. Can. J. Zool. 85: 437-442. DOI: $10.1139 / \mathrm{Z} 07-016$

54. Paquet, P.C. \& Carbyn, L. 2003. Gray wolves. In: Feldhamer, G. \& Thompson, B. (eds.) Mammals of North America. Revised 2nd edition. Hopkins University Press, Baltimore, pp 482-510.

55. Bryan, H.M, Darimont, C.T., Reimchen, T.E. \& Paquet, P.C. 2006. Early ontogenetic diet of wolves. Can. Field Nat. 20: 61-66.

56. Darimont, C.T., Paquet, P.C. \& Reimchen, T.E. 2008. Spawning salmon disrupt tight trophic coupling between wolves and ungulate prey in coastal British Columbia. BMC Ecology 8: 14. DOI: $10.1186 / 1472-6785-8-14$

57. Darimont, C.T. \& Reimchen, T.E. 2002. Intra-hair stable isotope analysis implies seasonal shift to salmon in gray wolf diet. Can. J. Zool. 80: 1638-1642.

DOI: $10.1139 / \mathrm{z} 02-149$

58. Darimont, C.T., Reimchen, T.E. \& Paquet, P.C. 2003. Foraging behaviour by gray wolves on salmon streams in coastal British Columbia. Can. J. Zool. 81: 349-353.

DOI: $10.1139 / \mathrm{z} 02-246$

59. Newsome, S., Martínez del Rio, C., Bearhop, S. \& Phillips, D. 2007. A niche for isotopic ecology. Front. Ecol. Envir. 5: 429-436.

60. Polis, G.A. 1984. Age structure component of niche width and intraspecific resource partitioning: can age groups function as ecological species? Am. Nat. 123: 541-564.

DOI: $10.1086 / 284221$ 
61. Markman, S., Pinshow, B. \& Wright, J. 2002. The manipulation of food resources reveals sex-specific trade-offs between parental self-feeding and offspring care. Proc. R. Soc. B 269: 1931-1938. DOI: $10.1098 / \mathrm{rspb} .2002 .2118$

62. Endler, J.A. 1986. Natural selection in the wild. Monographs in population biology 21. Princeton University Press, Princeton.

63. Darimont, C.T., Paquet, P.C. \& Reimchen, T.E. 2007. Stable isotopic niche predicts fitness of prey in a wolf-deer system. Biol. J. Linn. Soc. 90: 125-137.

DOI: $10.1111 / \mathrm{j} .1095-8312.2007 .00716 . x$

64. Moritz, C. 1994. Defining ‘evolutionary significant units' for conservation. Trends Ecol. Evol. 9: 373-375. DOI: 10.1016/0169-5347(94)90057-4

65. Muñoz-Fuentes, V., Darimont, C.T., Wayne, R.K., Paquet, P.C. \& Leonard, J.A. In press. Ecological factors drive genetic differentiation in British Columbia gray wolves. J. Biogeogr.

66. Poulin, R. 1998. Evolutionary ecology of parasites: from individuals to communities. Chapman and Hall, London.

67. Craig, H.L. \& Craig, P.S. 2005. Helminth parasites of wolves (Canis lupus): a species list and an analysis of published prevalence studies in Nearctic and Palaearctic populations. J. Helminthol. 79: 95-103. DOI: $10.1079 / \mathrm{JOH} 2005282$

68. Bryan, H.M., Paquet, P.C., Darimont, C.T. \& Smits, J.E. 2007. Disease ecology of sympatric wolves and dogs in coastal British Columbia. 56th annual meeting of the Wildlife Disease Association. Estes Park, Colorado. Abstract.

69. Smith, D.W. \& Ferguson, G. 2006. Decade of the wolf: returning the wild to Yellowstone. Lyons Press, Guildford.

70. Farnsworth, E.J. \& Rosovsky, J. 1993. The ethics of ecological field experimentation. Conserv. Biol. 7: 463-472.

DOI: 10.1046/j.1523-1739.1993.07030463.x

71. Cuthill, I. 1991. Field experiments in animal behaviour: methods and ethics. Anim. Behav. 42: 1007-1014. DOI: $10.1016 / \mathrm{S} 0003-3472(05) 80153-8$

72. Arnemo, J.M., Ahlqvist, P., Andersen, R., Berntsen, F., Ericsson, G., Odden, J., Brunberg, S., Segerström, P. \& Swenson, J.E. 2006. Risk of capture-related mortality in large free-ranging mammals: experiences from Scandinavia. Wildl. Biol. 12: 109-113. DOI: 10.2981/0909-6396(2006)12[109:ROCMIL]2.0.CO;2

73. Cattet, M., Boulanger, J., Stenhouse, G., Powell, R.A. \& Reynolds-Hogland, M.J. 2008. An evaluation of long-term capture effects in ursids: implications for wildlife welfare and research. Journal of Mammalogy 89: 973-990.

DOI: 10.1644/08-MAMM-A-095.1

74. Vucetich, J.A. \& Nelson, M.P. 2007. What are 60 warblers worth? Killing in the name of conservation. Oikos 116: 1267-1278.

DOI: $10.1111 / \mathrm{j} .0030-1299.2007 .15536 . x$

75. Kellert, S.R. 1993. The biological basis for human values of nature. In: Kellert, R. \& Wilson, E.O (eds). The Biophilia Hypothesis. Island Press, Washington, pp 42-69.

76. Oelfke, J.G. \& Wright, R.G. 2000. How long do we handle wolves in the Isle Royale wilderness? Park Science 20:14-18.

77. Weber, B. 2007. Suffering beluga opens hidden debate. AOL news. Canadian Press. June 02, 2007.

78. Paquet, P.C., \& Darimont, C.T. Accepted. Wildlife conservation meets animal welfare. Animal Welfare. 